OPEN ACCESS

Edited by:

Phyo Kyaw Myint University of Aberdeen,

United Kingdom

Reviewed by:

Candice Delcourt,

University of

New South Wales, Australia

Qi Li,

First Affiliated Hospital of Chongqing

Medical University, China

*Correspondence:

$\mathrm{HaO} \mathrm{LI}$

Ihmed514@163.com

Specialty section

This article was submitted to

Stroke,

a section of the journal

Frontiers in Neurology

Received: 28 October 2020 Accepted: 29 December 2020

Published: 01 February 2021

Citation:

Li Y, Zhou H, Yang X, Zheng J,

Zhang F, Xu M and Li H (2021) Neck

Circumference Is Associated With

Poor Outcome in Patients With

Spontaneous Intracerebral

Hemorrhage.

Front. Neurol. 11:622476

doi: 10.3389/fneur.2020.622476

\section{Neck Circumference Is Associated With Poor Outcome in Patients With Spontaneous Intracerebral Hemorrhage}

\author{
Yujian $\mathrm{Li}^{1}$, Huiqing Zhou ${ }^{2}$, Xiang Yang ${ }^{1}$, Jun Zheng ${ }^{1}$, Fan Zhang ${ }^{1}$, Mangmang $X u^{3}$ and \\ $\mathrm{HaO} \mathrm{Li}^{1 *}$ \\ 1 Department of Neurosurgery, West China Hospital, Sichuan University, Chengdu, China, ${ }^{2}$ Department of Intensive Care \\ Unit, Fourth People's Hospital of Sichuan Province, Chengdu, China, ${ }^{3}$ Department of Neurology, West China Hospital, \\ Sichuan University, Chengdu, China
}

Objective: This study aimed to assess the association between neck circumference (NC) and functional outcome in intracerebral hemorrhage $(\mathrm{ICH})$ patients.

Methods: We prospectively analyzed data from $\mathrm{ICH}$ patients who received treatment at our institution from January 2018 to November 2019. Patients were categorized into two groups according to 180-day modified Rankin scale (MRS) scores. Univariate and multivariate analyses were performed to assess whether NC was associated with poor outcome in $\mathrm{ICH}$ patients. Receiver operating characteristic (ROC) curve analysis was performed to determine the significance of $\mathrm{NC}$ in predicting the functional outcome of $\mathrm{ICH}$ patients.

Results: A total of 312 patients were enrolled in our study. Multivariate logistic regression analysis indicated that NC was an independent predictor of poor 180-day functional outcome [odds ratio $(\mathrm{OR})=1.205,95 \%$ confidence interval $(\mathrm{Cl}): 1.075-1.350, p$ $=0.001]$. ROC analysis revealed that NC could predict poor functional outcome at 6 months.

Conclusions: NC is an independent predictor of unfavorable functional outcome at 6 months in $\mathrm{ICH}$ patients.

Keywords: prognosis, predictor, obesity, neck circumference, intracerebal hemorrhage

\section{INTRODUCTION}

Spontaneous intracerebral hemorrhage (ICH) is a devastating health event accounting for 10-15\% of all strokes $(1,2)$ and has characteristics of high mortality and morbidity and limited treatment options (3). Obesity is one of the major risk factors for stroke (4) and is associated with increased morbidity and mortality in the general population $(5,6)$. However, obesity appears to confer a survival advantage in patients with certain diseases, including heart failure, coronary artery disease, and chronic kidney disease (7-9). In addition, recent studies have linked this phenomenon, known as the "obesity paradox," to ICH $(10,11)$. 
Body mass index (BMI) is an indicator that is most commonly used to assess obesity. However, previous studies have shown that neck circumference (NC) could be used as a simple, feasible, and stable evaluation index because it is not easily affected by eating or body position $(12,13)$. In addition, NC is related to oropharyngeal fat infiltration, which narrows the upper respiratory tract (14). However, little is known about the role of $\mathrm{NC}$ in patients with ICH. The purpose of this study was to explore the relationship between $\mathrm{NC}$ and the prognosis of $\mathrm{ICH}$.

\section{MATERIALS AND METHODS}

\section{Patients}

We defined the inclusion criteria as follows: (1) a diagnosis of intracranial hemorrhage using computed tomography (CT), (2) routine blood examination and laboratory tests conducted within $24 \mathrm{~h}$ after admission, and (3) age $\geq 18$ years. Patients who met the following criteria were excluded: (1) $\mathrm{ICH}$ attributable to aneurysm, arteriovenous malformation, or Moyamoya disease; (2) ICH attributable to acute cerebral infarction or thrombolysis of cerebral or myocardial infarction; (3) prior systemic diseases, such as immunological disease, neurological disease, recent infectious disease, severe hepatic or renal dysfunction, and coagulation dysfunction; (4) patients with isolated intraventricular hemorrhage (IVH); and (5) patients with a history of neck surgery. Brain CT angiography (CTA) or magnetic resonance angiography (MRA) was used to exclude aneurysm, arteriovenous malformation, or Moyamoya disease.

\section{Clinical and Laboratory Parameters}

Baseline clinical and demographic parameters, including NC, $\mathrm{BMI}$, height-to-NC ratio (HNR), age, sex, medical history, Glasgow Coma Scale (GCS) score on admission, blood pressure, cigarette and alcohol use, history of stroke, medical history of hypertension, diabetes mellitus, and history of endotracheal intubation and tracheotomy, were collected at hospital arrival.

Laboratorial variables, including white blood cells (WBCs), platelets, blood glucose, cholesterol, high-density lipoprotein cholesterol (HDL-C), and low-density lipoprotein cholesterol (LDL-C), were also recorded. NC $(\mathrm{cm})$ was measured to the nearest $1 \mathrm{~mm}$ with plastic tape. The tape was placed as horizontally as possible, at a point below the larynx (thyroid cartilage) and perpendicular to the long axis of the neck (keep the tape line on the front of the neck at the same height as the tape line on the back of the neck, Figure 1). Two reviewers independently estimated the values of NC. Any disagreement between the two reviewers was resolved by consensus. Height (m) and weight $(\mathrm{kg})$ were measured at the bedside by trained staff on admission using a tape measure and a digital weight scale, respectively, and BMI was calculated according to the standard formula $\left(\mathrm{kg} / \mathrm{m}^{2}\right)$. Admission HNR was calculated as the ratio of the height to the NC.

Radiological results collected from head CT within $24 \mathrm{~h}$ after admission to the hospital included hematoma location, hematoma size, and the presence of IVH. Hematoma volume was measured by the $\mathrm{ABC} / 2$ method as described previously (15). Two reviewers independently estimated all the head CT

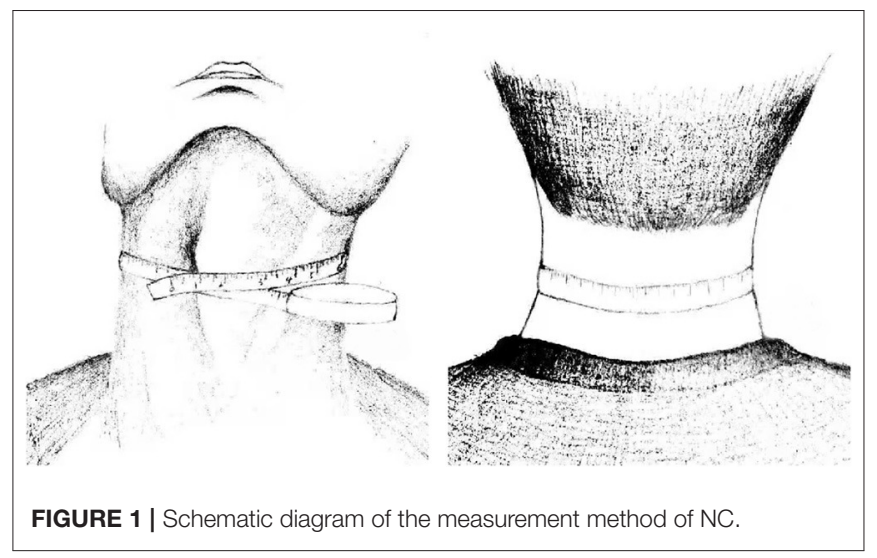

scans. Any disagreement between the two reviewers was resolved by consensus.

The functional outcome was assessed according to the 180day modified Rankin scale (MRS) score obtained by telephone or during outpatient visits. An MRS score $\geq 3$ was defined as an unfavorable outcome, including severe disability, persistent vegetative state, and death.

\section{Statistical Analysis}

All baseline characteristics, including clinical variables, laboratory parameters, and radiological data, were compared between patients with poor outcomes and those with favorable outcomes. Continuous variables are expressed as mean \pm standard deviation or median with interquartile range (IQR) for normally distributed and non-normally distributed variables, respectively, whereas categorical variables are expressed as frequency and percentage. Univariate analyses were conducted by independent $t$-test, Mann-Whitney $U$-test, chi-square $\left(\chi^{2}\right)$ test, or Fisher's exact test. Independent $t$-tests or Mann-Whitney $U$-tests were applied to compare continuous variables. The chi-square $\left(\chi^{2}\right)$ test or Fisher's exact test was used to compare categorical data. Variables significant at the $p<0.20$ level in the univariate analysis were retained in the multivariate model. For interpretation purposes, some variables were classed as follows: GCS score as " $13-15$ points," " $9-12$ points," and " $3-8$ points"; and hematoma location as "lobe," "basal ganglia," "thalamus," "cerebellum," and "brainstem." Receiver operating characteristic (ROC) analysis was performed to indicate the predictive value of $\mathrm{NC}$ for the functional outcome of $\mathrm{ICH}$ patients. The cut-off value of NC was decided by the Youden index from the ROC curve, and sensitivity and specificity were used to calculate the Youden index (sensitivity + specificity -1 ). A value of $p<0.05$ was considered statistically significant. All the above-mentioned statistical analyses were performed by SPSS version 21.0 (SPSS, Chicago, IL, USA).

\section{RESULT}

From January 2018 to November 2019, 312 consecutive patients (229 males and 83 females) with spontaneous ICH who met the 


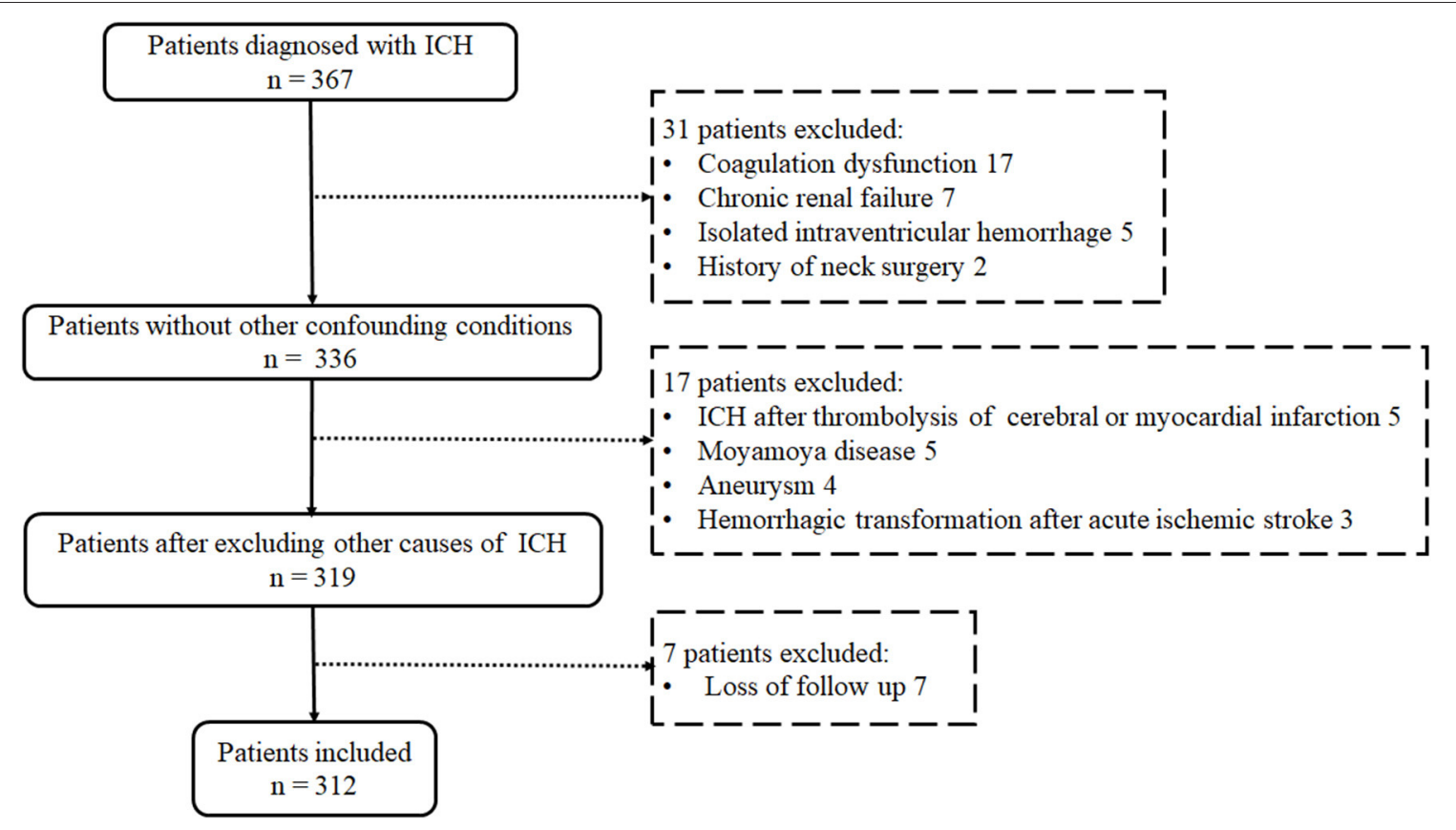

FIGURE 2 | Flowchart of study enrolment.

inclusion criteria were enrolled in this prospective study, and the rate of loss to follow-up was $2 \%$ (7/319, Figure 2).

The univariate analysis showed that patients with poor functional outcome at 6 months had higher NC $(p=0.007)$, higher $\operatorname{HNR}(p=0.015)$, higher hematoma size $(p<0.001)$, higher WBC count $(p<0.001)$, higher blood glucose level $(p=$ $0.005)$, lower age $(p=0.036)$, and lower GCS score on admission $(p<0.001)$. The proportions of patients with IVH (31.7 vs. $50.8 \%, p=0.001$ ), endotracheal intubation (26.8 vs. $67.7 \%, p$ $<0.001$ ), and tracheotomy (9.8 vs. $27.0 \%, p<0.001$ ), as well as patients with basal ganglia hemorrhage ( 40.7 vs. $55.0 \%)$ and brainstem hemorrhage (13.0 vs. $25.4 \%$ ), were higher in the poor outcome group (Table 1). The multivariate analysis indicated that higher $\mathrm{NC}(\mathrm{OR}=1.205,95 \% \mathrm{CI}: 1.075-1.350, p=0.001)$, lower BMI (OR $=0.829,95 \% \mathrm{CI}: 0.722-0.953, p=0.009)$, GCS 9-12 points ( $\mathrm{OR}=4.139,95 \% \mathrm{CI}: 1.912-8.960, p<0.001)$, GCS $3-8$ points (OR $=57.537,95 \% \mathrm{CI}: 15.725-210.526, p<0.001)$, larger hematoma size $(\mathrm{OR}=1.062,95 \% \mathrm{CI}: 1.034-1.092, p<$ 0.001 ), basal ganglia hemorrhage (OR $=6.300$, 95\% CI: $2.285-$ $17.375, p<0.001$ ), and brainstem hemorrhage ( $\mathrm{OR}=16.223$, 95\% CI: $3.226-81.572, p=0.001)$ were significantly correlated with poor functional outcome at 6 months (Table 2). ROC curve analysis showed that $\mathrm{NC}$ could predict poor functional outcome with an area under the curve of 0.591 (95\% CI: $0.527-0.655, p$ $=0.007$, Figure 3 ). The value of $39.45 \mathrm{~cm}$ for $\mathrm{NC}$ was the best cut-off for predicting the functional outcome of ICH patients according to the Youden index, and the specificity, sensitivity, positive predictive value, and negative predictive value of $\mathrm{NC}$ for predicting poor outcome were 41.5, 71.5, 55, and 59.3\%, respectively. In addition, we found that the proportions of poor outcomes in patients with $\mathrm{NC} \geq 39.45 \mathrm{~cm}$ and patients with $\mathrm{NC}$ $<39.45 \mathrm{~cm}$ were 63.1 and $55.1 \%$, respectively.

\section{DISCUSSION}

To the best of our knowledge, this is the first study that focused on $\mathrm{NC}$ in patients with $\mathrm{ICH}$. We found that $\mathrm{NC}$ was an independent risk factor for poor ICH prognosis, and that BMI was independently inversely associated with poor outcome in $\mathrm{ICH}$ patients. NC is an indicator of obesity that reflects health (16-21). Previous studies have shown that NC is associated with an increased risk of hypertension (18), diabetes (17, 21), and metabolic syndrome (19). NC is also found to be associated with congestive heart failure incidence and coronary heart disease mortality (20). However, research regarding the association between NC and ICH is limited.

According to the "obesity paradox," obese and overweight stroke patients have a more favorable prognosis than those with a normal or lower BMI (22-24). Consistent with these findings, we found that BMI was independently inversely associated with poor outcome in $\mathrm{ICH}$ patients. Interestingly, we also found a contradictory relationship between $\mathrm{BMI}$ and $\mathrm{NC}$ in predicting the prognosis of ICH. One possible explanation for the paradoxical phenomenon may be that the two obesity indicators reflect different fat distributions. BMI only reflects total body obesity, and NC represents an alternative method for measuring upper body subcutaneous fat (25). Moreover, it has been demonstrated that NC is associated with oropharyngeal fatty infiltration, which narrows the upper airway, resulting in obstructive sleep apnea (OSA) (14). 
TABLE 1| Univariate analysis of clinical characteristics related to 180-day outcome in patients with $\mathrm{ICH}$.

\begin{tabular}{|c|c|c|c|}
\hline Characteristic & $\begin{array}{c}\text { Favorable } \\
\text { outcome }(n= \\
123)\end{array}$ & $\begin{array}{l}\text { Poor outcome } \\
\qquad(n=189)\end{array}$ & $p$-value \\
\hline $\mathrm{NC}(\mathrm{cm})$ & $41.01 \pm 4.79$ & $42.46 \pm 4.68$ & $0.007^{*}$ \\
\hline $\mathrm{BMI}\left(\mathrm{kg} / \mathrm{m}^{2}\right)$ & $25.46 \pm 4.29$ & $26.14 \pm 3.75$ & 0.142 \\
\hline HNR & $4.03 \pm 0.41$ & $3.92 \pm 0.37$ & $0.015^{\star}$ \\
\hline Age (years) & $61(49,70)$ & $56(46,67)$ & $0.036^{\star}$ \\
\hline Sex (male) & $86(69.9 \%)$ & $143(75.7 \%)$ & 0.262 \\
\hline Hypertension & 99 (80.5\%) & $164(86.8 \%)$ & 0.136 \\
\hline Diabetes mellitus & $12(9.8 \%)$ & $9(4.8 \%)$ & 0.085 \\
\hline Prior stroke & $3(2.4 \%)$ & $10(5.3 \%)$ & 0.260 \\
\hline Smoking & $40(32.5 \%)$ & $52(27.5 \%)$ & 0.343 \\
\hline Alcohol consumption & $26(21.1 \%)$ & 54 (28.6\%) & 0.142 \\
\hline $\mathrm{SBP}(\mathrm{mmHg})$ & $161.70 \pm 29.90$ & $165.74 \pm 27.98$ & 0.207 \\
\hline DBP (mmHg) & $94.58 \pm 17.96$ & $98.43 \pm 17.74$ & 0.063 \\
\hline $\begin{array}{l}\text { GCS score on } \\
\text { admission }\end{array}$ & - & - & $<0.001^{* *}$ \\
\hline $13-15$ & 80 (65.0\%) & 27 (14.3\%) & - \\
\hline $9-12$ & 38 (30.9\%) & $58(30.7 \%)$ & - \\
\hline $3-8$ & $5(4.1 \%)$ & 104 (55.0\%) & - \\
\hline $\mathrm{ICH}$ location & - & - & $<0.001^{\star *}$ \\
\hline Lobe & 32 (26.0\%) & 17 (9.0\%) & - \\
\hline Basal ganglia & $50(40.7 \%)$ & 104 (55.0\%) & - \\
\hline Thalamus & $18(14.6 \%)$ & $16(8.5 \%)$ & - \\
\hline Cerebellum & 7 (5.7\%) & $4(2.1 \%)$ & - \\
\hline Brainstem & $16(13.0 \%)$ & 48 (25.4\%) & - \\
\hline Hematoma size (ml) & $15.0(6.2,27.3)$ & $\begin{array}{c}31.9(15.3 \\
55.8)\end{array}$ & $<0.001^{* *}$ \\
\hline Presence of IVH & 39 (31.7\%) & $96(50.8 \%)$ & $0.001^{*}$ \\
\hline Endotracheal intubation & $33(26.8 \%)$ & 128 (67.7\%) & $<0.001^{\star \star}$ \\
\hline Tracheotomy & $12(9.8 \%)$ & $51(27.0 \%)$ & $<0.001^{* *}$ \\
\hline WBC, $\times 10^{9}$ & $9.98 \pm 3.88$ & $12.39 \pm 4.09$ & $<0.001^{\star}$ \\
\hline Platelet, $\times 10^{9}$ & $173.98 \pm 60.66$ & $181.21 \pm 69.63$ & 0.347 \\
\hline Blood glucose (mmol/l) & $7.75 \pm 2.89$ & $8.68 \pm 2.75$ & $0.005^{\star}$ \\
\hline Cholesterol (mmol/l) & $4.47 \pm 1.08$ & $4.43 \pm 1.19$ & 0.758 \\
\hline HDL-C (mmol/l) & $1.35 \pm 0.43$ & $1.32 \pm 0.52$ & 0.568 \\
\hline LDL-C (mmol/l) & $2.61 \pm 0.77$ & $2.59 \pm 0.98$ & 0.854 \\
\hline
\end{tabular}

Values are expressed as $n$ (\%), mean \pm standard deviation, and median (25, 75\%), as appropriate. ${ }^{\star} p<0.05 .{ }^{* *} p<0.001 . \mathrm{ICH}$, intracerebral hemorrhage; $N C$, neck circumference; BMI, body mass index; HNR, height-to-NC ratio; SBP, systolic blood pressure; $D B P$, diastolic blood pressure; GCS, Glasgow Coma Scale; $I \mathrm{VH}$, intraventricular hemorrhage; WBC, white blood cell; HDL-C, high-density lipoprotein cholesterol; LDL-C, low-density lipoprotein cholesterol. Bold indicates $p<0.05$.

A retrospective study found that among individuals with a larger $\mathrm{NC}$ ( $\geq 43.2 \mathrm{~cm}$ in men and $\geq 36.8 \mathrm{~cm}$ in women), the incidence of OSA was 2.52 times higher in men and 3.13 times higher in women (26). It was reported that compared with BMI, NC better explained the change in apnea-hypopnea index in morbidly obese women $(n=115)$ in the predictive model (27). OSA had been reported to be associated with ICH. The hypoxia and hemodynamic responses associated with OSA may predispose patients to stroke (28). Moreover, OSA was associated
TABLE 2 | Multivariate analysis of predictors for poor outcome at 6 months.

\begin{tabular}{|c|c|c|}
\hline Predictors & OR (95\% Cl) & $p$-value \\
\hline NC (per $1 \mathrm{~cm}$ increase) & $1.205(1.075-1.350)$ & $0.001^{*}$ \\
\hline BMl (per 1 kg/m² increase) & $0.829(0.722-0.953)$ & $0.009^{*}$ \\
\hline GCS score on admission & - & - \\
\hline GCS (13-15 points) & Reference & - \\
\hline GCS (9-12 points) & $4.139(1.912-8.960)$ & $<0.001^{* *}$ \\
\hline GCS (3-8 points) & 57.537 (15.725-210.526) & $<0.001^{\star *}$ \\
\hline $\mathrm{ICH}$ location & - & - \\
\hline Lobe & Reference & - \\
\hline Basal ganglia & $6.300(2.285-17.375)$ & $<0.001^{\star *}$ \\
\hline Thalamus & $3,751(0.856-16.444)$ & 0.080 \\
\hline Cerebellum & $0.363(0.045-2.893)$ & 0.338 \\
\hline Brainstem & $16.223(3.226-81.572)$ & $0.001^{*}$ \\
\hline Hematoma size (per $1 \mathrm{ml}$ increase) & $1.062(1.034-1.092)$ & $<0.001^{\star \star}$ \\
\hline Presence of IVH & $3.176(1.476-6.834)$ & $0.003^{*}$ \\
\hline
\end{tabular}

NC, neck circumference; BMI, body mass index; GCS, Glasgow Coma Scale; ICH, intracerebral hemorrhage; $\mathrm{NH}$, intraventricular hemorrhage. Bold indicates $p<0.05$. ${ }^{*} p$ $<0.05,{ }^{\star \star} p<0.001$.

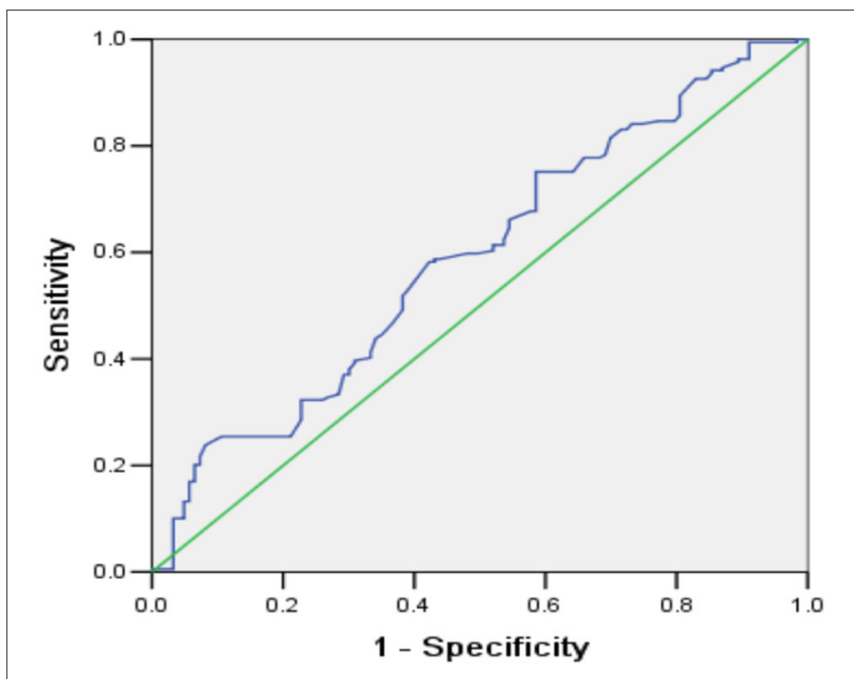

FIGURE 3 | Receiver operating characteristic curve for the predictive value of $\mathrm{NC}$ for functional outcome in $\mathrm{ICH}$ patients at 6 months.

with the development of perihematoma edema (29), which may cause poor outcomes after ICH (30-32). Several mechanisms may influence the development of encephaledema after ICH. The early stage of cerebral edema occurs in the first few hours after ICH and involves hydrostatic pressure induced by the formation of hematoma and retraction of the clot. The second phase, caused by the production of thrombin and activation of the coagulation cascade, occurs within the first $24 \mathrm{~h}$, and the delayed stage involves red blood cell hemolysis and hemoglobininduced toxicity $(33,34)$. The sizes of perihematoma edema have also been related to several factors, such as the level of serum ferritin and increased matrix metalloproteinase- 9 activity, which 
is an important enzyme for blood-brain barrier remodeling and perihematoma edema development (35-38).

Due to a momentary cessation of breathing, OSA patients with this disorder have repeated episodes of hypoxia/reoxygenation, promoting systemic oxidative stress, clotting cascade activation, inflammation, and damaged repair competence of the vascular endothelium (39). Thus, through the above several pathways, OSA may play a role in the generation of perihematoma edema. Moreover, OSA has been demonstrated to be associated with the enhanced activity of matrix metalloproteinase-9. Therefore, it is reasonable to believe that the association between OSA and perihematoma edema is biologically plausible.

Mechanical ventilation after tracheotomy or endotracheal intubation may prevent OSA-related hypoxia. However, a previous study reported that in acute spontaneous $\mathrm{ICH}$ patients, endotracheal intubation and mechanical ventilation were associated with an increased risk of hospital-acquired pneumonia and in-hospital mortality (40). Consistently, in the present study, we found that the proportions of patients with tracheotomy and endotracheal intubation were higher in the poor outcome group. The reason may be that the hematoma volume in ICH patients with tracheotomy or endotracheal intubation was larger than that in patients without tracheotomy or endotracheal intubation, which suggested a more severe condition and poorer prognosis.

In addition, previous studies have shown that $\mathrm{NC}$ was associated with an increased risk of hypertension (18), diabetes $(17,21)$, and metabolic syndrome (19), which also played a role in the occurrence and development of ICH (41-43). Furthermore, Pezzini et al. found that obesity, mainly through its indirect effect on hypertension and obesity-related complications, played a role in ICH (44). NC should not be overlooked in evaluating $\mathrm{ICH}$ patients.

Since NC was proven to predict poor outcome in patients with $\mathrm{ICH}$, the potential clinical significance should be further studied. First, as an indicator of obesity, it is easy and convenient to obtain NC in clinical practice, especially among patients with poor coordination. Moreover, NC is related to oropharyngeal fat infiltration, which narrows the upper respiratory tract. For $\mathrm{ICH}$ patients with consciousness disturbance, NC can be used to evaluate endotracheal intubation or tracheotomy to keep the airway open. In addition, since a single predictor of outcome in ICH patients has limitations, several prognostic scores have been used to predict functional outcome and mortality in this population (45). Similarly, the combination of NC and other predictive factors can form new prediction scores with higher specificity and sensitivity. However, the potential clinical implications of NC should be further investigated.

However, our study has several limitations. First, this study collected data from one hospital, with a limited sample

\section{REFERENCES}

1. Qureshi AI, Tuhrim S, Broderick JP, Batjer HH, Hondo H, Hanley DF, et al. Spontaneous intracerebral hemorrhage. N Engl J Med. (2001) 344:145060. doi: 10.1056/NEJM200105103441907 size, which may lead to selection bias. Second, NC is one of the factors causing upper respiratory tract stenosis, and the presence of other unmeasured factors will influence our final conclusion. Third, OSA was not accurately assessed in our study. Finally, all ICH patients were only from a West China Hospital, and patients with poor clinical conditions were usually recruited because of the medical referral system.

\section{CONCLUSION}

$\mathrm{NC}$ is an independent predictor of unfavorable functional outcome at 6 months. Further experiments are necessary to explore the specific mechanism.

\section{DATA AVAILABILITY STATEMENT}

The raw data supporting the conclusions of this article will be made available by the authors, without undue reservation.

\section{ETHICS STATEMENT}

The studies involving human participants were reviewed and approved by the ethics committee of West China Hospital of Sichuan University. The patients/participants provided their written informed consent to participate in this study.

\section{AUTHOR CONTRIBUTIONS}

YL and HL designed the project. YL performed the statistical analyses and wrote the manuscript draft. YL, HZ, FZ, JZ, XY, MX, and HL screened and extracted the data. All authors have made an intellectual contribution to the manuscript and approved the submission.

\section{FUNDING}

This work was supported by the National Natural Science Foundation of China (grant no. 81801186), Science and Technology Department of Sichuan Province (grant no. 2020YFQ0009), and Outstanding Subject Development 135 Project of West China Hospital, Sichuan University (grant no. ZY2016102).

\section{ACKNOWLEDGMENTS}

Thanks to Tingting Zhang for drawing the schematic diagram for us.

2. Qureshi AI, Mendelow AD, Hanley DF. Intracerebral haemorrhage. Lancet. (2009) 373:1632-44. doi: 10.1016/S0140-6736(09)60371-8

3. Broderick J, Connolly S, Feldmann E, Hanley D, Kase C, Krieger $\mathrm{D}$, et al. Guidelines for the management of spontaneous intracerebral hemorrhage in adults: 2007 update: a guideline from the American 
Heart Association/American Stroke Association Stroke Council, High Blood Pressure Research Council, and the Quality of Care and Outcomes in Research Interdisciplinary Working Group. Stroke. (2007) 38:200123. doi: 10.1161/STROKEAHA.107.183689

4. Strazzullo P, D'Elia L, Cairella G, Garbagnati F, Cappuccio FP, Scalfi L, et al. Excess body weight and incidence of stroke: meta-analysis of prospective studies with 2 million participants. Stroke. (2010) 41:e41826. doi: 10.1161/STROKEAHA.109.576967

5. Whitlock G, Lewington S, Sherliker P, Clarke R, Emberson J, Halsey J, et al. Body-mass index and cause-specific mortality in 900000 adults: collaborative analyses of 57 prospective studies. Lancet. (2009) 373:108396. doi: 10.1016/S0140-6736(09)60318-4

6. Pischon T, Boeing H, Hoffmann K, Bergmann M, Schulze MB, Overvad K, et al. General and abdominal adiposity and risk of death in Europe. $N$ Engl J Med. (2008) 359:2105-20. doi: 10.1056/NEJMoa0801891

7. Schmidt D, Salahudeen A. The obesity-survival paradox in hemodialysis patients: why do overweight hemodialysis patients live longer? Nutr Clin Pract. (2007) 22:11-5. doi: 10.1177/011542650702200111

8. Romero-Corral A, Montori VM, Somers VK, Korinek J, Thomas RJ, Allison TG, et al. Association of bodyweight with total mortality and with cardiovascular events in coronary artery disease: a systematic review of cohort studies. Lancet. (2006) 368:666-78. doi: 10.1016/S0140-6736(06)69251-9

9. Horwich TB, Fonarow GC, Hamilton MA, MacLellan WR, Woo MA, Tillisch JH. The relationship between obesity and mortality in patients with heart failure. J Am Coll Cardiol. (2001) 38:789-95. doi: 10.1016/S0735-1097(01)01448-6

10. Dangayach NS, Grewal HS, De Marchis GM, Sefcik RK, Bruce R, Chhatlani A, et al. Does the obesity paradox predict functional outcome in intracerebral hemorrhage? J Neurosurg. (2018) 129:1125-9. doi: 10.3171/2017.5.JNS163266

11. Sun W, Xian Y, Huang Y, Sun W, Liu R, Li F, et al. Obesity is associated with better survival and functional outcome after acute intracerebral hemorrhage. J Neurol Sci. (2016) 370:140-4. doi: 10.1016/j.jns.2016.09.029

12. Laakso M, Matilainen V, Keinänen-Kiukaanniemi S. Association of neck circumference with insulin resistance-related factors. Int J Obes Relat Metab Disord. (2002) 26:873-5. doi: 10.1038/sj.ijo.0802002

13. Onat A, Avci GS, Barlan MM, Uyarel H, Uzunlar B, Sansoy V. Measures of abdominal obesity assessed for visceral adiposity and relation to coronary risk. Int J Obes Relat Metab Disord. (2004) 28:1018-25. doi: 10.1038/sj.ijo.0802695

14. Godoy IR, Martinez-Salazar EL, Eajazi A, Genta PR, Bredella MA, Torriani M. Fat accumulation in the tongue is associated with male gender, abnormal upper airway patency and whole-body adiposity. Metab Clin Exp. (2016) 65:1657-63. doi: 10.1016/j.metabol.2016.08.008

15. Webb AJ, Ullman NL, Morgan TC, Muschelli J, Kornbluth J, Awad IA, et al. Accuracy of the $\mathrm{ABC} / 2$ score for intracerebral hemorrhage: systematic review and analysis of MISTIE, CLEAR-IVH, and CLEAR III. Stroke. (2015) 46:24706. doi: 10.1161/STROKEAHA.114.007343

16. Kwon HM, Park JH, Park JH, Jeong HY, Lim JS, Jeong HG, et al. Visceral fat is an independent predictor of cerebral microbleeds in neurologically healthy people. Cerebrovasc Dis. (2016) 42:90-6. doi: 10.1159/000445300

17. Yang GR, Yuan SY, Fu HJ, Wan G, Zhu LX, Bu XL, et al. Neck circumference positively related with central obesity, overweight, and metabolic syndrome in Chinese subjects with type 2 diabetes: Beijing Community Diabetes Study 4. Diabetes Care. (2010) 33:2465-7. doi: 10.2337/dc10-0798

18. Kuciene R, Dulskiene V, Medzioniene J. Association of neck circumference and high blood pressure in children and adolescents: a case-control study. BMC Pediatr. (2015) 15:127. doi: 10.1186/s12887-015-0444-2

19. Alzeidan R, Fayed A, Hersi AS, Elmorshedy H. Performance of neck circumference to predict obesity and metabolic syndrome among adult Saudis: a cross-sectional study. BMC Obes. (2019) 6:13. doi: 10.1186/s40608-019-0235-7

20. Zhang J, Guo Q, Peng L, Li J, Gao Y, Yan B, et al. The association of neck circumference with incident congestive heart failure and coronary heart disease mortality in a community-based population with or without sleep-disordered breathing. BMC Cardiovasc Disord. (2018) 18:108. doi: 10.1186/s12872-018-0846-9

21. Anothaisintawee T, Sansanayudh N, Thamakaison S, Lertrattananon D, Thakkinstian A. Neck circumference as an anthropometric indicator of central obesity in patients with prediabetes: a cross-sectional study. Biomed Res Int. (2019) 2019:4808541. doi: 10.1155/2019/4808541

22. Doehner W, Schenkel J, Anker SD, Springer J, Audebert HJ. Overweight and obesity are associated with improved survival, functional outcome, and stroke recurrence after acute stroke or transient ischaemic attack: observations from the TEMPiS trial. Eur Heart J. (2013) 34:26877. doi: 10.1093/eurheartj/ehs340

23. Kim BJ, Lee SH, Ryu WS, Kim CK, Lee J, Yoon BW. Paradoxical longevity in obese patients with intracerebral hemorrhage. Neurology. (2011) 76:56773. doi: 10.1212/WNL.0b013e31820b7667

24. Vemmos K, Ntaios G, Spengos K, Savvari P, Vemmou A, Pappa T, et al. Association between obesity and mortality after acute first-ever stroke: the obesity-stroke paradox. Stroke. (2011) 42:30-6. doi: 10.1161/STROKEAHA.110.593434

25. Salmanroghani H, Salmanroghani R, Nourian M, Khayarn K, Lahmi F, Iravani S. Evaluation of neck circumference as an easy and reliable predictor for non-alcoholic fatty liver disease. Turk J Gastroenterol. (2019) 30:16370. doi: 10.5152/tjg.2018.18004

26. Earl DE, Lakhani SS, Loriaux DB, Spector AR. Predictors of moderate to severe obstructive sleep apnea: identification of sex differences. Sleep Breath. (2019) 23:1151-8. doi: 10.1007/s11325-019-01790-x

27. Gasa M, López-Padrós C, Monasterio C, Salord N, Mayos M, Vilarrasa $\mathrm{N}$, et al. Anthropometrical phenotypes are important when explaining obstructive sleep apnea in female bariatric cohorts. J Sleep Res. (2019) 28:e12830. doi: $10.1111 /$ jsr. 12830

28. Dyken ME, Somers VK, Yamada T, Ren ZY, Zimmerman MB. Investigating the relationship between stroke and obstructive sleep apnea. Stroke. (1996) 27:401-7. doi: 10.1161/01.STR.27.3.401

29. Pontes-Neto OM, Fernandes RM, Sander HH, da Silva LA, Mariano DC, Nobre F, et al. Obstructive sleep apnea is frequent in patients with hypertensive intracerebral hemorrhage and is related to perihematoma edema. Cerebrovasc Dis. (2010) 29:36-42. doi: 10.1159/000255972

30. Urday S, Beslow LA, Dai F, Zhang F, Battey TW, Vashkevich $A$, et al. Rate of perihematomal edema expansion predicts outcome after intracerebral hemorrhage. Crit Care Med. (2016) 44:790-7. doi: 10.1097/CCM.0000000000001553

31. Grunwald Z, Beslow LA, Urday S, Vashkevich A, Ayres A, Greenberg SM, et al. Perihematomal edema expansion rates and patient outcomes in deep and lobar intracerebral hemorrhage. Neurocrit Care. (2017) 26:20512. doi: $10.1007 / \mathrm{s} 12028-016-0321-3$

32. Yang J, Arima H, Wu G, Heeley E, Delcourt C, Zhou J, et al. Prognostic significance of perihematomal edema in acute intracerebral hemorrhage: pooled analysis from the intensive blood pressure reduction in acute cerebral hemorrhage trial studies. Stroke. (2015) 46:100913. doi: 10.1161/STROKEAHA.114.007154

33. Xi G, Keep RF, Hoff JT. Pathophysiology of brain edema formation. Neurosurg Clin N Am. (2002) 13:371-83. doi: 10.1016/S1042-3680(02)00007-4

34. Gebel JM, Jauch EC, Brott TG, Khoury J, Sauerbeck L, Salisbury S, et al. Relative edema volume is a predictor of outcome in patients with hyperacute spontaneous intracerebral hemorrhage. Stroke. (2002) 33:263641. doi: 10.1161/01.STR.0000035283.34109.EA

35. Abilleira S, Montaner J, Molina CA, Monasterio J, Castillo J, Alvarez-Sabín J. Matrix metalloproteinase- 9 concentration after spontaneous intracerebral hemorrhage. J Neurosurg. (2003) 99:65-70. doi: 10.3171/jns.2003.99.1.0065

36. Alvarez-Sabín J, Delgado P, Abilleira S, Molina CA, Arenillas J, Ribó $\mathrm{M}$, et al. Temporal profile of matrix metalloproteinases and their inhibitors after spontaneous intracerebral hemorrhage: relationship to clinical and radiological outcome. Stroke. (2004) 35:1316-22. doi: 10.1161/01.STR.0000126827.69286.90

37. Mehdiratta M, Kumar S, Hackney D, Schlaug G, Selim M. Association between serum ferritin level and perihematoma edema volume in patients with spontaneous intracerebral hemorrhage. Stroke. (2008) 39:1165-70. doi: 10.1161/STROKEAHA.107. 501213

38. Lou M, Lieb K, Selim M. The relationship between hematoma iron content and perihematoma edema: an MRI study. Cerebrovasc Dis. (2009) 27:26671. doi: $10.1159 / 000199464$ 
39. Jelic S, Le Jemtel TH. Inflammation, oxidative stress, and the vascular endothelium in obstructive sleep apnea. Trends Cardiovasc Med. (2008) 18:253-60. doi: 10.1016/j.tcm.2008.11.008

40. Lioutas VA, Marchina S, Caplan LR, Selim M, Tarsia J, Catanese L, et al. Endotracheal intubation and in-hospital mortality after intracerebral hemorrhage. Cerebrovasc Dis. (2018) 45:270-8. doi: 10.1159/0004 89273

41. Boulanger M, Poon MT, Wild SH, Al-Shahi Salman R. Association between diabetes mellitus and the occurrence and outcome of intracerebral hemorrhage. Neurology. (2016) 87:870-8. doi: 10.1212/WNL.0000000000 003031

42. Mitaki S, Takayoshi H, Nakagawa T, Nagai A, Oguro H, Yamaguchi $\mathrm{S}$. Metabolic syndrome is associated with incidence of deep cerebral microbleeds. PLoS ONE. (2018) 13:e0194182. doi: 10.1371/journal.pone.01 94182

43. Chung PW, Kim JT, Sanossian N, Starkmann S, Hamilton S, Gornbein J, et al. Association between hyperacute stage blood pressure variability and outcome in patients with spontaneous intracerebral hemorrhage. Stroke. (2018) 49:348-54. doi: 10.1161/STROKEAHA.117.0 17701
44. Pezzini A, Grassi M, Paciaroni M, Zini A, Silvestrelli G, Iacoviello $\mathrm{L}$, et al. Obesity and the risk of intracerebral hemorrhage: the multicenter study on cerebral hemorrhage in Italy. Stroke. (2013) 44:1584-9. doi: 10.1161/STROKEAHA.111.000069

45. Gregório T, Pipa S, Cavaleiro P, Atanásio G, Albuquerque I, Chaves P, et al. Assessment and comparison of the four most extensively validated prognostic scales for intracerebral hemorrhage: systematic review with meta-analysis. Neurocrit Care. (2019) 30:449-66. doi: 10.1007/s12028-018-0633-6

Conflict of Interest: The authors declare that the research was conducted in the absence of any commercial or financial relationships that could be construed as a potential conflict of interest.

Copyright (c) $2021 \mathrm{Li}$, Zhou, Yang, Zheng, Zhang, Xu and Li. This is an open-access article distributed under the terms of the Creative Commons Attribution License (CC $B Y)$. The use, distribution or reproduction in other forums is permitted, provided the original author(s) and the copyright owner(s) are credited and that the original publication in this journal is cited, in accordance with accepted academic practice. No use, distribution or reproduction is permitted which does not comply with these terms. 